\title{
La profesión de Turismo Ecológico en la Universidad de Costa Rica: Un análisis desde la perspectiva de su población graduada
}

Núñez Masís, Luis Carlos; Marín Alfaro, Anyerline

La profesión de Turismo Ecológico en la Universidad de Costa Rica: Un análisis desde la perspectiva de su población graduada

Revista Educación, vol. 42, núm. 2, 2018

Universidad de Costa Rica, Costa Rica

Disponible en: http://www.redalyc.org/articulo.oa?id=44055139011

DOI: https://doi.org/10.15517/revedu.v42i2.24477

Esta obra está bajo una Licencia Creative Commons Atribución-NoComercial-SinDerivar 3.0 Internacional. 


\title{
La profesión de Turismo Ecológico en la Universidad de Costa Rica: Un análisis desde la perspectiva de su población graduada
}

\author{
The Ecotourism profession at the University of Costa Rica: An Analysis from the Perspective of its Graduate \\ Population
}

Luis Carlos Núñez Masis [1]

Universidad de Costa Rica, Costa Rica

luiscarlos.nunez@ucr.ac.cr

http://orcid.org/0000-0002-5260-1460

Anyerline Marin Alfaro [2]

Universidad de Costa Rica, Costa Rica

angerline.marin@ucr.ac.cr
DOI: https://doi.org/10.15517/revedu.v42i2.24477

Redalyc: http://www.redalyc.org/articulo.oa?id=44055139011

\section{ReSUMEN:}

Se describe la percepción general de la población graduada del Bachillerato en Turismo Ecológico y Licenciatura en Gestión Ecoturística de la Universidad de Costa Rica, acerca de su proceso de formación en esta disciplina, así como sobre su desempeño profesional. La metodología abordó un enfoque cuantitativo y se trabajó con una muestra de 251 personas que obtuvieron su título entre 1995 y el año 2014, la cual es de tipo probabilística estratificada, considera la cantidad total de personas graduadas de cada unidad académica donde obtuvieron su diploma como un estrato; se utilizó una base de datos con información de contacto de todas las personas tituladas de la carrera y se aplicó un cuestionario en línea. Los resultados muestran la opinión acerca de su formación, con resultados satisfactorios, sobre el grado de uso de los conocimientos, habilidades y actitudes del perfil profesional, sobresale la aplicación de la teoría del desarrollo sostenible y su aplicación al turismo; en relación con las características académicas que requieren para un mejor desempeño laboral, son los idiomas como el inglés, el francés o el alemán; entre las áreas prioritarias del contexto donde la carrera debe incidir, destaca apoyar a las microempresas y comunidades vulnerables del turismo; y entre los mecanismos para fortalecer la inserción destaca la práctica profesional. Se exponen aspectos relacionados con la permanencia en el mercado laboral y, finalmente, se evidencian las necesidades y se proponen diversas acciones para mejorar el quehacer académico de esta disciplina. El estudio resulta relevante y constituye un referente para el proceso de mejoramiento de la carrera en todas las unidades académicas donde se imparte. La dificultad de la investigación radicó en contactar a los sujetos egresados, una población de difícil acceso.

PALABras Clave: Ecoturismo, mercado laboral, educación superior, necesidades de educación, perfil profesional, estudiantado graduado.

\section{Abstract:}

This article aims at describing the general perception of the graduates of the Bachelor degree in Ecological Tourism and the Licentiate Degree in Ecotourism Management at the University of Costa Rica about their formation process in this discipline as well as on their professional performance. The methodology addressed a quantitative approach and used a sample of 251 students who graduated from 1995 to 2014 . The sampling technique implemented was the stratified probability type, considering the total number of graduates of each academic unit where they obtained their diploma as the sample. A database with contact information of all graduates of the mayor was used as well as a questionnaire, which was applied online. The results show their opinions about their formation, the use of the knowledge acquired, skills and attitudes of their professional profile, the application of sustainable development theory and its application to tourism; In relation to the academic characteristics required to perform better in the job market, to the languages like English, French to German; Among the priority areas of the context where the career should be

\section{NotAS DE AUTOR}

[1] Bachiller en Turismo Ecológico y Máster en Gestión Hotelera, de la Universidad de Costa Rica. Profesor en la carrera de Bachillerato en Turismo Ecológico y Licenciatura en Gestión Ecoturística en el recinto de Golfito de la Universidad de Costa Rica.

[2] Bachiller en Turismo Ecológico y Licenciada en Gestión Ecoturística de la Universidad de Costa Rica, Máster en Administración de Proyectos. Profesora en la carrera de Bachillerato en Turismo Ecológico y Licenciatura en Gestión Ecoturística en el recinto de Grecia de la Universidad de Costa Rica. 
focused, it is important to support micro-entrepreneurs and vulnerable communities of tourism; And among the mechanisms to strengthen the insertion of professional practice. They are exposed related to the permanence in the labor market and finally, the needs are evidenced and several actions are proposed to improve the academic work of this discipline. The study is relevant and constitutes a reference for the process of improvement of the career in all academic units where it is taught. The difficulty of the investigation was to contact the graduates, a population of difficult access.

KEYWORDS: ecotourism, job market, higher education, education needs, professional profile, graduates.

El artículo realiza un análisis de la perspectiva del estudiantado graduado de Turismo Ecológico en la Universidad de Costa Rica acerca de su perfil profesional, así como del quehacer académico de esta disciplina. Tiene como propósito generar una base diagnóstica a partir de la percepción de las personas graduadas que facilite y fundamente la actualización integral del plan de estudios de la carrera de Bachillerato en Turismo Ecológico y Licenciatura en Gestión Ecoturística, necesidades evidenciadas en la autoevaluación y en el compromiso de mejoramiento con miras a la acreditación, realizados mediante el modelo establecido por el Sistema Nacional de Acreditación de la Educación Superior (SINAES). El proceso se desarrolló a lo largo de 6 años (Comisión de Autoevaluación de Turismo Ecológico, 2013).

La necesidad de mejora en medio de un contexto educativo con importantes retos en temas de regulación de la educación y aumento de la calidad llevó a la carrera a iniciar un proceso innovador de autoevaluación, realizado de manera conjunta entre todas las sedes y recintos donde se imparte dicha opción académica, con la asesoría del Centro de Evaluación Académica (CEA), de la Universidad de Costa Rica. Esto permitió un profundo análisis de todos los actores y derivó en el desarrollo de un plan de mejoras que considera ejes de trabajo relacionados con la gestión de la carrera, el plan de estudios, la inserción laboral, la investigación y la acción social (Comisión de Autoevaluación de Turismo Ecológico, 2014).

Para Almonacid, Montes y Vásquez (2009, p.101), se debe analizar "la pertinencia de los programas académicos de educación superior, permite identificar la relación de la Universidad, los graduados y el entorno, y sugerir acciones de mejoramiento al interior de las instituciones de educación superior", ya que estos dan cuenta de la pertinencia de su formación.

En relación con el plan de estudios, esta disciplina responde a necesidades importantes para el desarrollo nacional y la realidad global (Arce y Chaverri, 2015; Global Sustainable Tourism Council, 2016; Instituto Costarricense de Turismo, 2012). Por lo tanto, desde la institución se hace necesario verificar que los conocimientos, habilidades y destrezas de la población graduada se ajusten a las necesidades del contexto ambiental, social y económico, nacional e internacional.

Esta disciplina tiene una trayectoria corta y resulta indispensable realizar procesos de retroalimentación que le permitan, a la institución, identificar la percepción de las nuevas generaciones de profesionales en torno a su proceso formativo, así como sobre la forma en que este proceso les ha permitido desenvolverse en el ámbito laboral y hacer efectivos los propósitos que originalmente la Universidad se planteó.

\section{ANTECEDENTES}

Para responder a una realidad y necesidades del contexto turístico nacional, la Universidad de Costa Rica, de manera visionaria y con una decisión de vanguardia, creó en el año 1991 la carrera de Bachillerato en Turismo Ecológico, con los objetivos de "favorecer por medio del turismo ecológico, el desarrollo socio económico, cultural y científico del país, y a la vez permitir así el logro de beneficios regionales como el resultado de las orientaciones que promueve el desarrollo sostenible", así como, "formar profesionales con conocimientos en las ciencias naturales y sociales, para la planificación, la formulación de políticas y la toma de decisiones en el campo del turismo ecológico" (Universidad de Costa Rica, 1991, p. 4). 
Uno de los principios básicos en la creación de la carrera es el deseo institucional de "contribuir a un desarrollo inclusivo que tienda a crear soluciones viables para las economías locales, favoreciendo a los grupos sociales de la región Chorotega y de aquellas regiones menos favorecidas del país, mediante la generación de empleo" (Universidad de Costa Rica, 1991, p. 2).

Los retos que asumió la Universidad de Costa Rica son claros, la población graduada debe incidir en el modelo de desarrollo que se gesta alrededor del turismo costarricense para favorecer a las comunidades locales mediante los principios del desarrollo sostenible; para ello, el titulado debe tener la capacidad de asumir tareas dentro de su rol laboral enmarcadas en la creación, la planificación, el manejo y la gestión del turismo ecológico, tanto en el sector público, privado, estatal y en organizaciones no gubernamentales, todo desde la visión humanista que caracteriza el modelo de formación de la Universidad de Costa Rica.

Para lograr este cometido, la persona profesional en turismo ecológico debe poseer una serie de conocimientos y habilidades como parte de su formación académica, que le permitan ejercer adecuadamente sus labores, no limitándose exclusivamente a la atención y operación de la actividad turística, sino incidir desde las bases de la actividad.

De acuerdo con el Consejo Nacional de Rectores (1990), la carrera de Bachillerato en Turismo Ecológico nace en la Sede de Guanacaste de la Universidad de Costa Rica en el año 1991. El éxito académico de esta, así como el incremento en la actividad turística costarricense, contribuyeron para que la profesión iniciara un proceso paulatino de crecimiento y desconcentración en otras sedes y recintos universitarios ubicados en zonas geográficas donde el turismo es una actividad económica de importancia, así la Tabla 1, muestra en el tiempo, la desconcentración de la carrera Bachillerato en Turismo Ecológico y su estado actual por unidad académica.

TABLA 1

Desconcentración de la carrera en Bachillerato en Turismo Ecológico

\begin{tabular}{lll}
\hline Sede o recinto & $\begin{array}{l}\text { Año de } \\
\text { desconcentración }\end{array}$ & Estado actual \\
\hline Sede de Limón & 1998 & Activa \\
Sede del Atlántico (Recinto Turrialba) & 2001 & Cerrada (2004) \\
Sede del Atlántico (Recinto de Paraíso) & 2007 & Activa \\
Sede del Pacífico & 2004 & Cerrada (2014) \\
Recinto de Golfito & 2007 & Activa \\
Recinto de Grecia & 2009 & Activa \\
\hline
\end{tabular}

Nota: Elaboración propia con base en la Comisión de Autoevaluación de Turismo Ecológico (2013).

De acuerdo con datos de la Oficina de Registro e Información de la Universidad de Costa Rica (2014), el incremento de la cantidad de unidades académicas que imparten esta disciplina incidió, de manera directa, en la cantidad de personas graduadas de esta profesión, pues entre 1995 y el año 2013 la cantidad anual aumentó en una proporción de 9,3 veces. La cifra mencionada sobrepasa el incremento porcentual registrado en la cantidad de títulos universitarios otorgados a nivel nacional durante ese mismo periodo, el cual fue tan solo 3,53 veces mayor (Ansorena, 2015).

La graduación de profesionales en Turismo Ecológico por parte de la Universidad de Costa Rica ha registrado un crecimiento irregular, caracterizado por aumentos y disminuciones pronunciadas, en particular debe mencionarse que en el año 2011 la oferta de individuos titulados aumentó en una relación de 4,9 veces en comparación con el año 2007, mientras tanto para el año 2014 disminuyó en una relación de 2,06 veces en comparación con el año 2013, situación que, sin lugar a dudas, afecta las posibilidades de inserción en el 
mercado laboral en especial durante los primeros años después de la culminación de sus estudios (Oficina de Registro e Información de la Universidad de Costa Rica, 2014).

\section{REFERENTES CONCEPTUALES}

La calidad de la educación universitaria se ha convertido en una premisa para las autoridades de la educación superior en el país, aspecto que ha derivado en diversas estrategias, tal es el caso de los procesos de acreditación de carreras desarrollado por el Sistema Nacional de Acreditación de la Educación Superior (SINAES), el programa del Estado de la Educación, el Observatorio Laboral de Profesiones, el proyecto de ley para la reforma del Consejo Nacional de Enseñanza Superior Universitaria Privada (CONESUP) propuesta por el Ministerio de Educación Pública (MEP), así como la labor de autoevaluación institucional de las mismas universidades, como en el caso de la Universidad de Costa Rica, ejercida por el Centro de Evaluación Académica (CEA) (Ansorena, 2015).

La calidad en educación superior debe ser abordada desde diversas conceptualizaciones y perspectivas, lo cual obliga no solo a meditar sobre la razón por la cual se deben crear las titulaciones universitarias, sino también a analizar las ideas y percepciones de los diversos actores que de distintas maneras se ven involucrados en los procesos de formación universitaria, como estudiantes; docentes; personal administrativo; entes empleadores; tendencias del contexto ambiental, social y económico en que está inmersa la disciplina y, por supuesto, estudiantado graduado. Este último grupo se constituye en sujetos evaluadores pero a la vez son fuente de evaluación, dados los resultados laborales, profesionales y trayectoria académica que presentan (Almonacid et al. 2009).

Lograr un proceso de evaluación en el que se atiendan las demandas de cada sector podría, quizás, entenderse como un sinónimo de calidad, el cual no debe ser estático, sino más bien el resultado de un constante proceso de revisión y de autoevaluación.

La autoevaluación y la evaluación externa radican en la necesidad de diseñar y ejecutar un plan de mejoramiento acorde con las particularidades de cada disciplina, el cual requiere ser elaborado de forma estratégica e integral y ejecutado desde la óptica de la mejora continua, de modo que sus ejes de trabajo deberán considerar elementos como la gestión administrativa de la carrera, la actualización de su plan de estudios para una congruencia integral, la investigación, la acción social, la incidencia sobre el contexto social, el perfil profesional y el empleo; en todos estos aspectos la percepción de la población graduada es de gran trascendencia. La forma en cómo la percepción de las personas graduadas incide en la mejoría de estos elementos se convierte en el objeto de análisis de este referente teórico.

De acuerdo con Roldán Santamaría (2005), los elementos necesarios para la actualización y congruencia de un plan de estudios deben ser dimensionados en el ámbito interno, donde se consideran los objetivos del plan confrontados con los fundamentos de la carrera, la viabilidad del plan en relación con los recursos disponibles, la relación entre los objetivos del plan con los objetivos de los cursos y la vigencia del plan. En el ámbito externo es donde se consideran las funciones que debe cumplir el grupo titulado, la revisión de los mercados de trabajo donde se identifican las demandas y el rol de la persona graduada en la solución de problemas de la comunidad a la cual dedica sus capacidades.

$\mathrm{Al}$ considerar los postulados anteriores, resulta comprensible que el plan de estudios de una disciplina se convierte en un eje medular de trabajo en todo proceso de mejora de una disciplina universitaria y debe estar en constante revisión para alcanzar su mayor grado de congruencia. La población de profesionales de una determinada disciplina son los sujetos informantes claves mediante los cuales se puede cotejar la congruencia del plan de estudios en particular en el ámbito externo.

De acuerdo con Guédez (1980), el perfil profesional de una determinada carrera universitaria se define como: 
El conjunto de características pretendidas por el empleador, las cuales deben reflejar las exigencias del mercado ocupacional, en términos de los requisitos que definan las habilidades, las destrezas, los rasgos de personalidad, la conformación física y el nivel de educación inherente al desempeño profesional. (p. 17)

Al respecto, Román y Morales (2015) analizaron la pertinencia de la oferta académica y el perfil profesional, según los entes empleadores de costarricenses con titulación universitaria y mencionan que:

Existe preocupación entre los empresarios por el costo de reentrenamiento y de las limitaciones que tendría un recurso humano formado para un puesto específico y carente de habilidades blandas. Lo acelerado de los cambios actuales sugiere la necesidad de una formación versátil y un recurso con gran capacidad de adaptación. (p. 220)

Los métodos para analizar la percepción del grupo graduado sobre su perfil pueden ser abordados desde distintas técnicas, por ejemplo Damián Simón y Arellano Mont (2009) analizaron las opiniones de 60 personas graduadas de las primeras cuatro generaciones de la carrera de Técnico Superior Universitario en Administración, para lo cual realizaron un muestreo aleatorio por estratos y aplicaron un cuestionario que consideró variables como el desempeño profesional, las actividades desarrolladas en el empleo actual y la opinión sobre su formación académica. Del estudio se lograron obtener importantes datos que evidenciaban virtudes y retos que la carrera debía asumir en torno al currículo, así como a mejoras sobre los conocimientos y habilidades en esta disciplina.

Otro ejemplo es el que utiliza Almonacid et al. (2009), quien evalúa la pertinencia de un programa académico desde la perspectiva de las personas graduadas a partir de dos modelos: el primero evalúa la percepción acerca de la pertinencia individual y la pertinencia social de su formación; mientras tanto el segundo modelo evalúa las competencias profesionales en cuanto a la percepción de su nivel de competencias instrumentales y sistémicas.

Puede deducirse que, por lo general, las preocupaciones primordiales del cuerpo de profesionales de una determinada disciplina giran en torno a la capacidad de inserción en puestos de mayor peso en el mercado laboral, así como a los conocimientos, habilidades y competencias que poseen para desempeñarse de forma óptima dentro del trabajo.

El estudio realizado por Suárez Lantarón (2014) sobre las condiciones de empleo de las personas españolas con titulación universitaria concluye que la labor de estimular y promover el empleo debe ser una responsabilidad compartida entre individuos, gobiernos, organizaciones e instituciones educativas, y que depende particularmente de una serie de los atributos que incluyen tanto conocimientos y habilidades, como atributos en la gestión de la carrera y la búsqueda de empleo. Además, indica que las universidades tanto públicas como privadas han buscado ajustar sus planes de estudio a las nuevas exigencias del contexto social y del mercado laboral, añadiendo nuevas competencias, así como estableciendo nuevos vínculos con los empleadores y desarrollando estrategias de orientación profesional que permitan una transición plena hacia el ámbito laboral.

Por su parte, Silas Casillas (2013) analiza los procesos de acreditación, el mercado y la educación superior en México y concluye:

Es preocupante que la valía de una institución de educación superior o de un programa formativo, que busca desarrollar a los jóvenes de un país, se mida a través de un concepto eficientista y mercantilizado de lo que significa la calidad y más aún, que este concepto se refuerce en la práctica a través de una acreditación. (p. 24)

Sin lugar a dudas, la información proporcionada a partir del análisis de las condiciones laborales de las personas graduadas universitarias facilita la toma de decisiones para el desarrollo de procesos de mejoramiento continuo en diversos ámbitos, tales como: fomentar el vínculo con el contexto social, la actualización de la malla curricular, el desarrollo de competencias, la contratación y capacitación del personal docente, la creación de estrategias didácticas y métodos de enseñanza, así como para fortalecer el grado de empleabilidad; pero no debe visualizarse como una forma mercantilizada de modelar los procesos de formación, dejando 
de lado los principios de autonomía y humanismo característicos del modelo de universidad pública costarricense.

Ruetzlera, Bakerb, Reynoldsc, Taylora y Allen (2014) realizaron un estudio con el interés de analizar las percepciones que tenía el conjunto de personas graduadas, el alumnado y el cuerpo docente universitario de la profesión de la hospitalidad y turismo en Estados Unidos, acerca de siete habilidades y conocimientos del perfil profesional seleccionadas de forma previa, los cuales eran requeridos por la industria. En las conclusiones se tiene que no existían coincidencias entre la importancia dada a cada característica por parte de los grupos. En el caso particular de la población graduada, esta otorga un mayor grado de importancia a la experiencia en el campo, en particular en cuanto a la adquirida en el ámbito de la comunicación oral, así como en la capacidad de administrar su tiempo, seguido por los conocimientos prácticos en la comunicación oral.

Toda mejora y actualización a la formación en Turismo Ecológico de la Universidad de Costa Rica debe responder, en primera instancia, a los principios institucionales en que se enmarca. En ese sentido, el Estatuto Orgánico versa:

La Universidad de Costa Rica debe contribuir con las transformaciones que la sociedad necesita para el logro del bien común, mediante una política dirigida a la consecución de una justicia social, de equidad, del desarrollo integral, de la libertad plena y de la total independencia de nuestro pueblo. (Universidad de Costa Rica, 1974, p. 1)

\section{Procedimientos metodológicos}

Esta investigación tiene un enfoque cuantitativo y un alcance descriptivo, a su vez plantea un diseño no experimental transversal (Hernández Sampieri, Fernández Collado y Baptista Lucio, 2014).

La población objetivo de estudio está compuesta por 728 personas graduadas del Bachillerato en Turismo Ecológico de las sedes de Guanacaste, Limón, Pacífico y Atlántico, así como de los recintos de Paraíso, Golfito y Grecia, esta se clasifica en cortes comprendidos entre la primera promoción graduada en el año 1995, hasta la cohorte correspondiente al año 2014. Se considera una sola vez a aquellas personas que obtuvieron más de un diploma, pero con distinto grado académico en esta misma disciplina, es decir, quienes obtuvieron el Bachillerato en Turismo Ecológico y la Licenciatura en Gestión Ecoturística se incluyen con el grado académico superior.

A partir de dicha población se realizó un proceso de muestreo, de tipo probabilístico estratificado, que considera la cantidad total de estudiantado graduado de cada unidad académica como un estrato, la Tabla 2 presenta la determinación del tamaño de la muestra, para su definición se utilizó el software Launch Stats 2.0. La definición del tamaño de la muestra tiene un margen de error máximo aceptable del $5 \%$ y un nivel de confianza del 95\%, así como un porcentaje estimado de la muestra del 50\%, a partir del cual se desprenden los siguientes datos:

TABLA 2

Determinación del tamaño de la muestra estratificada

\begin{tabular}{lcccccccc}
\hline Sede o recinto & Guanacaste & Caribe & Puntarenas & Turrialba & Paraíso & Golfito & Grecia & Total \\
\hline Población & 314 & 149 & 117 & 46 & 58 & 30 & 14 & 728 \\
Muestra & 108 & 52 & 40 & 16 & 20 & 10 & 5 & 251 \\
\hline
\end{tabular}

Nota; Elaboración propia.

Las unidades muestrales fueron seleccionadas de forma aleatoria mediante la utilización de números random; en caso de que a la hora de recolectar los datos, la unidad muestral seleccionada no fuera contactada, se procedió a realizar una nueva selección, de forma aleatoria, entre el resto de unidades que no fueron seleccionadas en un inicio. 
De acuerdo con la Oficina de Registro e Información de la Universidad de Costa Rica (2014), se generó una base de datos con los nombres de las 728 personas graduadas. Ya con las listas se procedió a completar los teléfonos y los correos electrónicos, para lo que se utilizó el Sistema de Aplicaciones Estudiantiles (SAE) de la misma universidad; sin embargo, fue fácil encontrar los datos actualizados de las últimas cinco generaciones graduadas, no así los contactos de las generaciones más antiguas, ya que en muchos casos los números de teléfono no estaban vigentes y sus correos electrónicos no correspondían o eran inexistentes. Por lo anterior, se procedió al uso de redes sociales y llamadas telefónicas.

Para la recolección de la información se construyó y aplicó un cuestionario en línea por medio del software FormSite.com, el cual incluyó preguntas con escalas de 1 a 5 donde 5 es la mejor calificación, así como, preguntas abiertas. A continuación, se presentan las categorías de análisis y las preguntas realizadas en cada una de ellas.

\section{A. Características sociodemográficas}

Se incluyeron preguntas como la edad, el sexo, el lugar de residencia y el estado civil, estas características permiten establecer una base para el análisis de la población en estudio.

\section{B. Estudios académicos}

¿Cuál es el grado de satisfacción que usted tiene en relación con su formación en turismo ecológico? ¿Qué otros conocimientos o habilidades en turismo ecológico cree usted que requiere para desempeñarse adecuadamente dentro del mercado laboral? ¿Cuáles cree usted que son áreas de prioridad para el desarrollo de futuras investigaciones o proyectos con el sector turismo?

\section{Ocupación}

Se presenta a la población una tabla con cuatro grandes variables de las características profesionales y cada una de estas incluye una serie de conocimientos, habilidades y actitudes profesionales adquiridas en la universidad, establecidas previamente en el plan de estudios de la carrera.

De acuerdo con los fines de creación de la carrera en Turismo Ecológico, usted adquirió la siguiente lista de conocimientos, habilidades y actitudes. En la columna de calificación indique el grado de uso de dichas características en su trabajo actual, para ello utilice una escala de 1 - 5 donde 5 es la más alta:

En relación con el desarrollo sostenible como promotor del bienestar socio económico:

- Frecuencia con que utiliza los recursos naturales para promover turismo.

- Frecuencia con que utiliza los recursos culturales para promover turismo.

- Frecuencia con que utiliza los datos socio económicos del país para promover el turismo.

- Frecuencia con que aplica los instrumentos metodológicos de la ecología para el desarrollo de proyectos.

- Frecuencia en que considera las necesidades de las comunidades para planificar el turismo.

- Frecuencia en que utiliza tecnologías amigables con la naturaleza

En relación con la utilización de la infraestructura existente:

- Frecuencia en que considera la complejidad del medio ambiente y la labor del ser humano en él.

- Frecuencia en la que se sensibiliza ante los problemas sociales y ambientales, y busca como resolverlos.

- Frecuencia en que logra identificar y evaluar las necesidades del país para desarrollar el ecoturismo. 
- Frecuencia en que organiza, dirige o coordina recorridos interpretativos de ecoturismo.

- Frecuencia en que utiliza el legado histórico, arqueológico, cultural, político y democrático para promover el ecoturismo.

En relación con el dominio de la comunicación:

- Frecuencia en que se relaciona y se comunica armoniosamente de manera interpersonal con turistas o personas afines al turismo

- Frecuencia en que se comunica en el idioma inglés.

En relación con el uso de técnicas administrativas:

- Frecuencia con la que aplica los principios de la administración turística.

- Frecuencia con que desarrolla estrategias de crecimiento para empresas turísticas.

- Frecuencia con que organiza o coordina el personal para desarrollar actividades turísticas.

- Frecuencia con que fija las prioridades y políticas para promover el turismo en un determinado lugar.

¿Cuáles mecanismos cree usted que la universidad puede desarrollar para favorecer la inserción y la permanencia de los profesionales en el mercado laboral del sector turismo?

\section{Impacto del estudiantado egresado en el medio turístico}

¿Cuál es el grado de satisfacción con su empleo actual?

De forma previa a su aplicación, el instrumento fue evaluado mediante juicio de personal experto y validado por personas graduadas, lo que permitió hacer los ajustes necesarios; la recolección de datos se extendió por un periodo de tres meses, tiempo en el cual se enviaron recordatorios semanales al estudiantado graduado vía correo electrónico, para la obtención total de las 251 respuestas de las personas incluidas en la muestra. El software formsite.com generó una hoja de cálculo, la cual facilitó el graficar y analizar los resultados finales.

De acuerdo con la Oficina de Registro e Información de la Universidad de Costa Rica (2014), la carrera de Bachillerato en Turismo Ecológico es una profesión que tiene tan solo 21 años de graduar profesionales, mientras que el grado de Licenciatura tiene solo 10, la mayoría de la población graduada ha obtenido su título en los últimos 5 años. Además, al analizar la edad de las personas graduadas se tiene que el 68,53\% son menores de 30 años y en relación con su estado civil el 63,35\% se encuentra en condición de soltería.

De las 728 personas graduadas hasta el año 2014, la mayoría son mujeres, quienes representan el 58,51\% de la población. Mientras tanto, al analizar la condición de residencia se obtiene que el 37,85\% vive en el Valle Central y el 30,28\% en la región Chorotega, el 9,16\% en el Pacífico Central, el 7,97\% en la región Huetar Caribe, el 7,57\% en la región Huetar Norte y el 6,37\% en la región Brunca, y solo un 0,80\% reside fuera del país.

Las características sociodemográficas de la población graduada de la carrera de Bachillerato en Turismo Ecológico y Licenciatura en Gestión Ecoturística coinciden con lo expuesto por el CONARE (citado por Ansorena, 2015), en donde se indica que la cantidad de mujeres matriculadas en esta profesión en la Universidad de Costa Rica supera en un $17 \%$ a la cantidad de hombres, que al ser comparada con el resto de profesiones de esta institución se ubica como la número 27 con mayor cantidad de mujeres matriculadas; además evidencia que a pesar de ofertarse en seis unidades académicas, su matrícula supera tan solo muy levemente a la de la mayoría de carreras, representa aproximadamente el 1,5\% de la totalidad de estudiantes con matrícula en el año 2014 y puede ser comparada con la matrícula de la carrera de Antropología, Comunicación o Enseñanza de las Matemáticas. 


\section{ANÁLISIS Y DISCUSIÓN DE RESULTADOS}

Opinión acerca de su formación en turismo ecológico

Se consultó a la población graduada, qué tan satisfecha se encontraba en cuanto a su formación en Turismo Ecológico en la Universidad de Costa Rica, utilizando una escala de 1 a 5 , donde 5 es la calificación más alta y 1 la más baja.

La Figura 1 muestra el promedio del grado de satisfacción hacia su formación en turismo ecológico según sede o recinto, el resultado que se obtuvo en general es satisfactorio, puesto que la puntuación asignada por las personas graduadas en esos aspectos es relativamente alta, alcanza un promedio de 3,49; sin embargo, al analizar la información por cada sede o recinto donde estas personas obtuvieron su título se tiene que la valoración promedio más baja acerca del grado de satisfacción hacia su formación en turismo ecológico la manifiestan las personas graduadas en la sede del Pacífico con una calificación de 2,98, mientras que las más altas corresponde a la sede de Turrialba con un 3,88 y el recinto de Grecia con un 3,80, levemente superior al promedio general, el cual es de 3,49. De acuerdo con la Comisión de Autoevaluación de Turismo Ecológico (2013), estos datos coinciden con la opinión de estudiantes que se consultaron en el proceso de autoevaluación de esta disciplina, donde se muestra un mayor grado de satisfacción hacia el liderazgo en la coordinación de la carrera en Recinto de Grecia con un 95\%, por el contrario, la Sede del Pacífico muestra un grado de satisfacción menor (13\%).

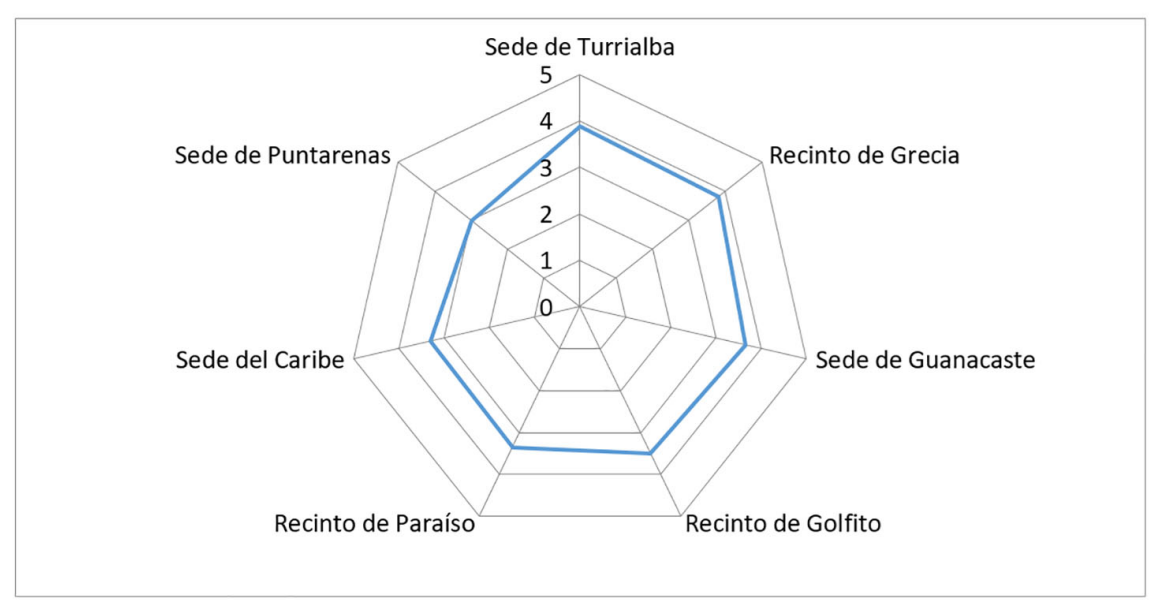

\section{FIGURA 1}

Promedio del grado de satisfacción hacia su formación en turismo ecológico según sede o recinto. Elaboración propia.

El grado de satisfacción de esta población hacia su formación en turismo ecológico es medianamente alto con un 3,49, levemente superior al promedio nacional que, de acuerdo con Gutiérrez Coto, Kikut Valverde, Navarro Cerdas, Azofeifa Ureña y Rodríguez Ramos (2015), es de 3,33. El estudio citado ubica la disciplina de turismo dentro de las ciencias sociales, las cuales obtuvieron una calificación general de 3,99; mientras tanto, el conjunto de carreras enfocadas con el manejo de los recursos naturales obtuvo una calificación general de 3,86 y las pertenecientes a las ciencias exactas como biología 3,65, las cuales son áreas vocacionales que guardan relación con la disciplina en cuestión. Lo anterior evidencia retos por asumir para mejorar el quehacer académico. 


\section{Grado de uso en el ámbito laboral de los conocimientos, habilidades y actitudes profesionales adquiridas en la carrera de turismo ecológico}

Durante el proceso de formación académica, la carrera dispone de un perfil profesional de salida que incluye conocimientos, habilidades y actitudes que se pretende sean las necesarias para el desarrollo pleno de cada profesional en el ámbito laboral; a partir de ello, resulta importante analizar la frecuencia de cómo esas características son utilizadas desde la perspectiva de su estudiantado graduado.

Se consultó al grupo de profesionales con qué frecuencia utilizaban estas características del perfil profesional, para ello se utilizó una escala de 1 a 5 , donde 5 es la calificación más alta y 1 la más baja, el resultado indica que la frecuencia promedio de uso de dichas habilidades es de 3,55 puntos, calificación medianamente aceptable. Los datos se presentan en la Figura 2.

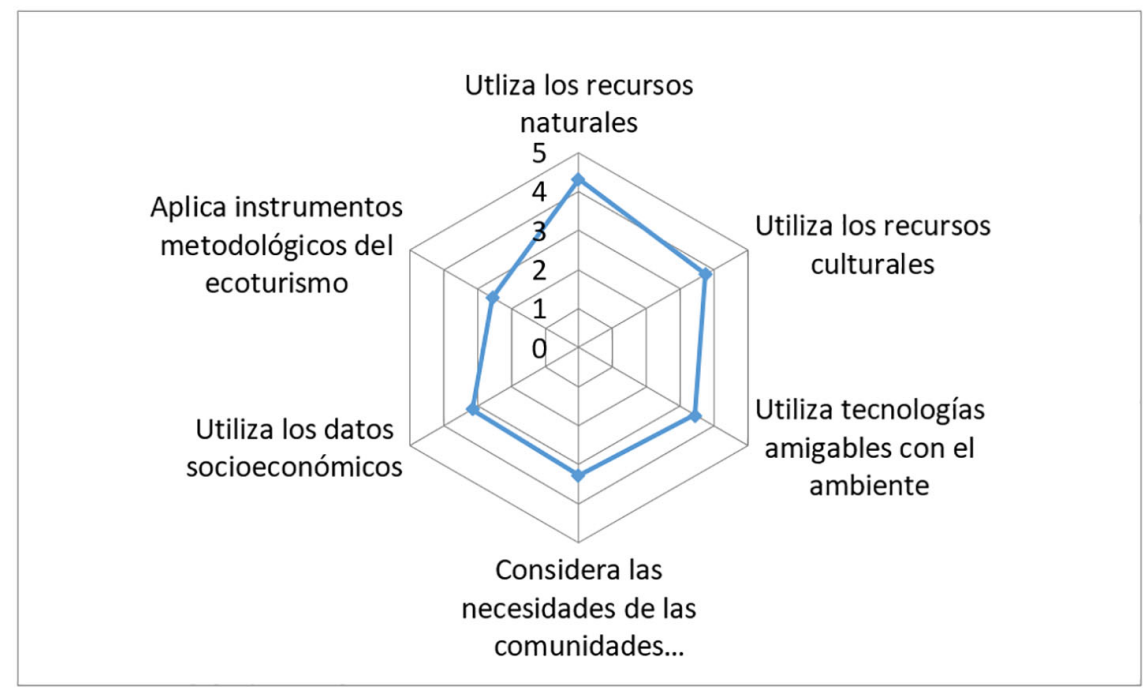

En el ámbito de la aplicación del desarrollo sostenible, eje medular de la disciplina, se encontró que el grupo de conocimientos, habilidades o actitudes más utilizadas en el trabajo, por parte de estas personas, son las relacionadas con la utilización de los recursos naturales, con una frecuencia de uso bastante alta de 4,31, muy superior al promedio. Los datos anteriores reflejan una situación en donde este grupo profesional, de manera frecuente, usa los recursos que forman parte del patrimonio turístico nacional para su función profesional, inspirado por las actitudes y valores morales que se desprenden del concepto desarrollo sostenible.

Referente al tema anterior, debe mencionarse que el ICT publicó el Plan Nacional de Desarrollo Turístico Sostenible 2002 - 2012, el cual plantea, desde la política pública, que "el desarrollo turístico sostenible es el medio por excelencia que el país tiene para utilizar eficientemente su acervo natural y cultural con el objetivo de generar riqueza que se traduzca en beneficios reales para toda la sociedad costarricense" (ICT, 2007. p. 8). Por otra parte, en el año 2008 se da el lanzamiento de los Criterios globales de turismo sostenible, con el propósito de fomentar una mayor comprensión de las prácticas de la actividad en todo el mundo (Global Sustainable Tourism Council, 2016). Los datos anteriores evidencian la pertinencia de la carrera y cómo la consolidación de políticas nacionales e internacionales se han ido afianzando años después de la creación de dicha opción académica, lo que, sin duda, debería facilitar y aligerar la colocación del estudiantado graduado en un mercado laboral que coincide cada vez más con su formación profesional.

De manera contraria, la aplicación de los instrumentos metodológicos del ecoturismo obtuvo una frecuencia de uso de 2,56, lo cual la constituye en la cualidad que obtuvo la menor calificación de todas las analizadas. Ello evidencia que la población graduada, en su mayoría, no desarrolla estudios de capacidad de carga turística, percepción ambiental, interpretación ambiental o evaluaciones de impacto ambiental, 
ya sea porque los puestos laborales que ocupan no requieren el ejercer tales tareas, o estas quizás son desarrolladas por otro personal experto, o bien porque esas técnicas no les resultan funcionales. Estos procesos metodológicos caracterizan el enfoque de gestión de la carrera, por lo que requieren ser analizados y fortalecidos para darles una mayor utilidad y potenciar su aplicación. En varios casos se deberán realizar convenios y enlaces con las instituciones o empresas relacionadas con el sector.

En la Figura 3 se analiza la manera cómo esta población de profesionales utiliza el patrimonio turístico en el ámbito laboral y se identifica que, frecuentemente, se sensibilizan ante los problemas sociales y ambientales y buscan cómo resolverlos, con una puntuación de 4,01, además consideran la complejidad del medio ambiente y la labor del ser humano en él, con 3,88; ambos son argumentos que de manera constante son necesarios para ejercer sus actividades laborales diarias, entendiéndose como parte de la conciencia ambiental compuesta de valores como el respeto hacia toda forma de vida. Estas características pueden considerarse como fundamentales para el desarrollo de modalidades de turismo inteligente que generan grandes aportes para el país, no solo en el ámbito ambiental, sino también en el plano socio económico y que podrían ser factores de éxito para la sostenibilidad de esta actividad en el largo plazo.

Gutiérrez Coto, et al. (2015) analizaron la importancia de distintas competencias genéricas de todo graduando en el trabajo, en el caso de las ciencias sociales, área en la cual ubicaron a la disciplina del turismo, se obtuvo un promedio ponderado de 4,05; además se determinó que más importantes son la capacidad de expresar verbalmente sus ideas, la capacidad para tomar decisiones e identificar, plantear y resolver problemas, mientras que la menos importante fue el manejo del inglés; aspecto que al contratarse con el ramo del turismo ecológico denota una diferencia radical, debido a que el manejo de esta lengua resulta indispensable.

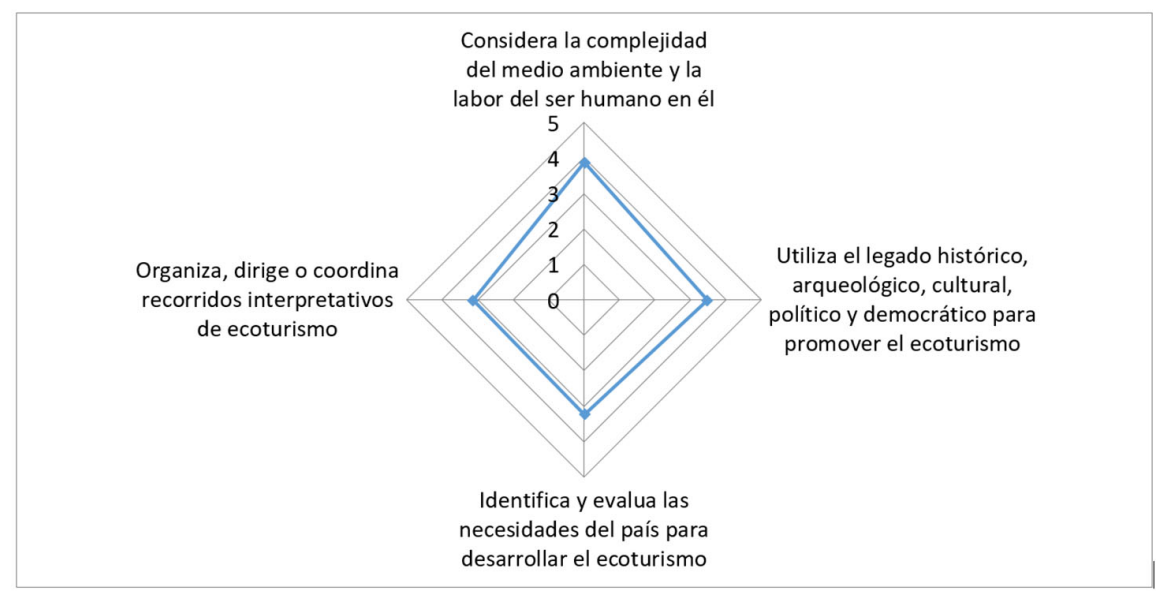

FIGURA 3

Promedio de utilización en el ámbito laboral de las habilidades y actitudes sobre el uso del patrimonio turístico. Elaboración propia.

El ecoturismo resulta una profesión interdisciplinaria en donde también se dota de conocimientos, habilidades y actitudes propios de la administración de empresas, sobre ello cabe mencionar que, de acuerdo con lo expresado por este grupo de personas, este conjunto de características aprendidas no son justamente las de mayor frecuencia de uso, puesto que obtuvieron un promedio de uso de 3,12; sin embargo, al analizar cada grupo de características por separado resulta que las de mayor uso es aplicar los principios de la administración de empresas turísticas con una calificación de 3,46 y la menos usada es fijar las prioridades y políticas para promover el turismo en un determinado lugar con una nota de 2,85.

Estas particularidades pueden ser utilizadas en mayor o menor medida a partir del tipo de empresas u organizaciones que están empleando al grupo de profesionales, así como, a partir del tipo de puestos que 
ocupan, en tanto, los de corte más técnico u operativo no requieren tanto de estas habilidades como si los mandos medios o los puestos gerenciales dentro de una organización.

En otro orden de ideas, al analizar el promedio de utilización de los conocimientos y habilidades sobre la comunicación en el ámbito laboral, la población titulada le asigna una calificación bastante alta de 4,36 a la frecuencia en que se relacionan y se comunican armoniosamente con turistas o personas afines al turismo, además asignan una calificación de 3,86 a la comunicación en idioma inglés.

$\mathrm{Al}$ ser el ecoturismo una disciplina en la cual en parte se gestiona una actividad económica que está basada en las experiencias humanas generadas alrededor de los atractivos y las relaciones interpersonales consideradas parte de un servicio, tiene una constante interacción entre seres humanos, donde el manejo de la comunicación asume un rol fundamental para garantizar la calidad (Arrieta Murillo y Rivera Hernández, 2011).

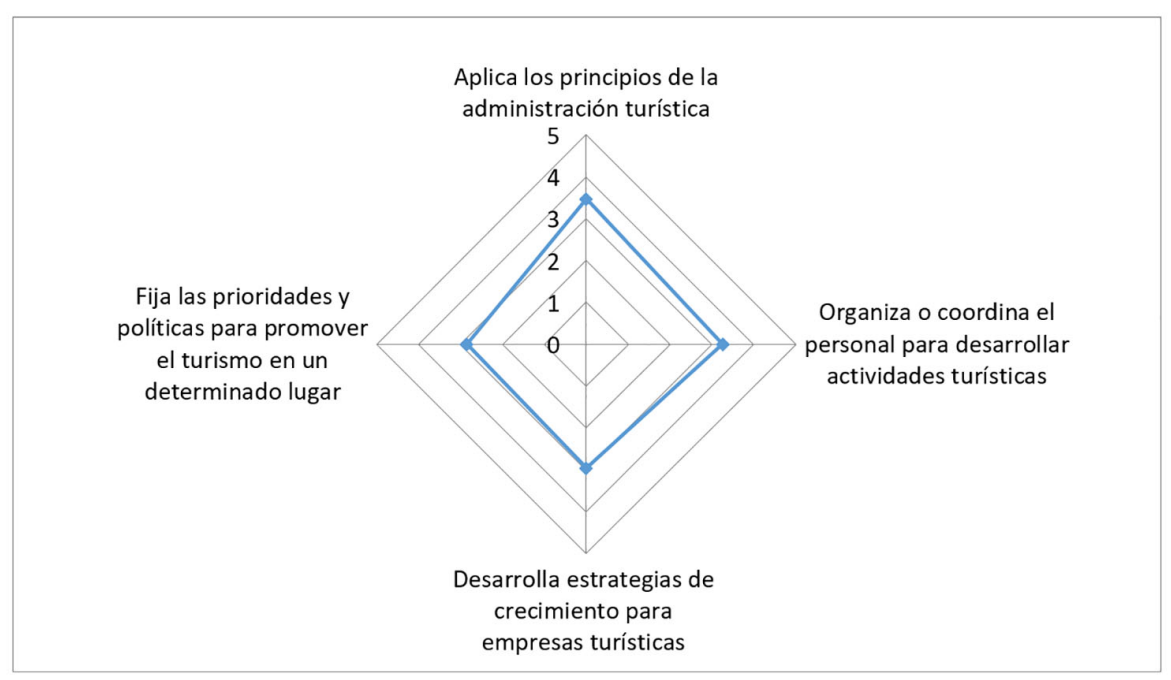

FIGURA 4

Promedio de la utilización en el ámbito laboral de los conocimientos, habilidades y actitudes sobre el uso de técnicas administrativas. Elaboración propia.

$\mathrm{Al}$ realizar un análisis integral del uso de estos conocimientos, habilidades y actitudes sobre el uso de técnicas administrativas en el ámbito laboral mostrada en la Figura 4, la población analizada demostró que los principios de la administración turística son los más aplicados, con una calificación de 3,46, seguida por la organización o coordinación de personal para desarrollar actividades turísticas 3,25; con la menor calificación de uso se encuentra el fijar prioridades y políticas para promover el turismo en un determinado lugar con una calificación de 2,85.

Existen ciertas habilidades que son utilizadas con mayor frecuencia que otras, su aplicación va a depender del gremio laboral en donde la persona profesional se desempeñe, así como del tipo de puesto de trabajo que ocupe, por lo que resulta necesario revisar con detalle aquellas que tienen poco uso e impulsar las más utilizadas como la comunicación con personas afines al turismo que obtuvo un 4,36 y el inglés un 3,86, además se evidencia la necesidad de incidir en el sector turístico, para que sus profesionales puedan ocupar puestos de trabajo que les permitan poner en práctica la mayoría de estas características relacionadas con la planificación, la creación, el manejo y la gestión del turismo en Costa Rica. 


\section{Impacto del estudiantado egresado en el medio turístico}

El impacto que el estudiantado graduado de la carrera de Turismo Ecológico de la Universidad de Costa Rica ha causado en el medio turístico costarricense puede medirse mediante los puestos laborales que dichas personas ocupan en las diversas empresas e instituciones.

Los resultados demuestran que el 28,47\% que trabaja en el sector turismo ha sido empleado por el gremio de las agencias de viajes, el 23,84\% labora en el sector público, mientras que el 21,19\% en el sector hospedaje, de modo tal que estos conforman los principales nichos empleadores de esta profesión. Al analizar los tipos de puestos que las personas graduadas han logrado ocupar dentro de los sectores mencionados se tiene que el 13,26\% ocupa un cargo gerencial, el 15, 92\% ocupa una jefatura o mando medio, el 47,78\% se desempeña como operario y el 3,53\% como asistente, finalmente el 18,58\% labora como docente, de los que debe mencionarse un 4,42\% forma parte del personal docente de la Universidad de Costa Rica, lo cual permite que sean parte del proceso de formación de nuevas generaciones de profesionales, así como que sean partícipes del proceso de actualización de la carrera, la creación de nuevas especialidades y miembros de los cuerpos colegiados de la institución.

Gutiérrez Coto et al. (2015) analizaron el grado de satisfacción con el empleo de las personas graduadas de las universidades costarricenses para la población graduada entre los años 2008 y 2010, para lo cual utilizaron una escala de $1-5$, donde 5 es la mejor calificación y 1 la peor, el resultado general arrojó un promedio de 4,36 puntos, lo cual puede catalogarse con muy satisfactorio. En el caso de profesionales que se graduaron de Turismo Ecológico, se obtuvo un promedio general de 4, lo cual aunque es menor que el promedio nacional, también puede catalogarse como muy satisfactorio, al analizar los datos según el gremio para el cual laboran se obtiene que en el sector público se obtienen las mejores calificaciones con un 4,52, seguido de las consultorías con una calificación de 4,4 y las agencias de viajes con 4,07 y como muestra la figura 5, es en las agencias de viajes y tour operadoras donde se emplea al mayor porcentaje de personas.

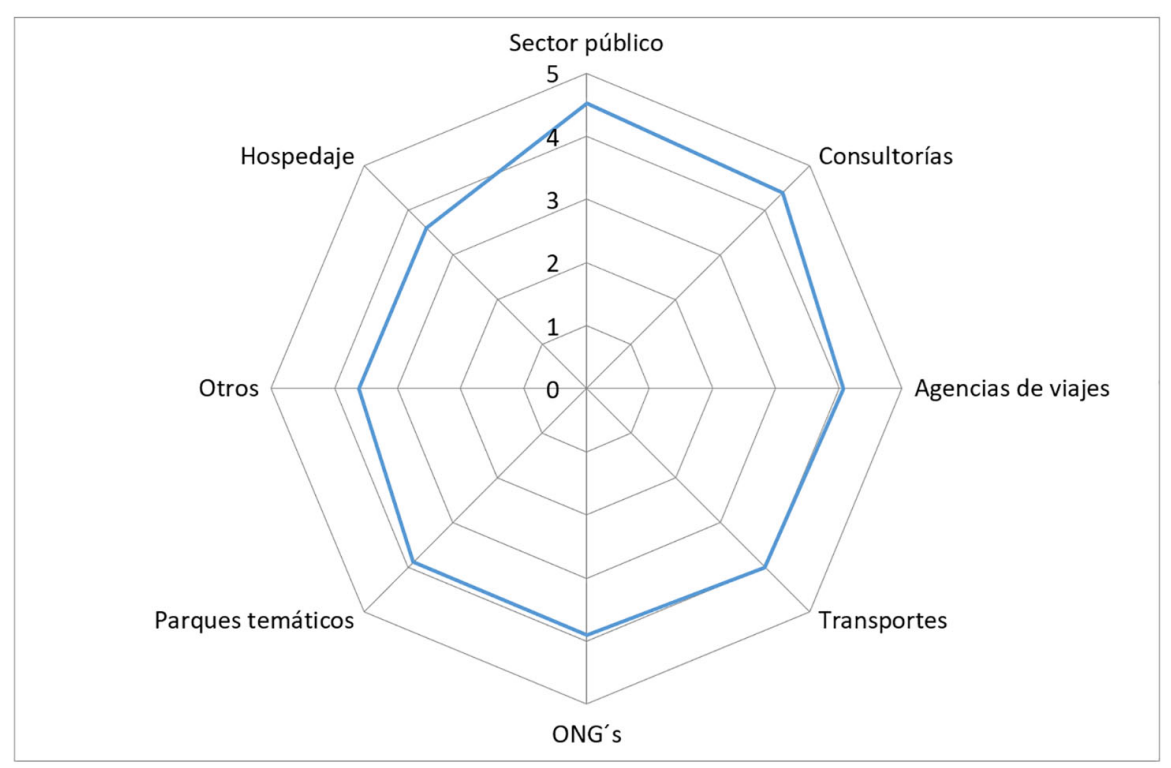

FIGURA 5

Satisfacción promedio de la población graduada hacia su empleo en turismo. Elaboración propia.

Los primeros años de experiencia laboral son un periodo de maduración y obtención de experiencia que les ayudarán en la consecución de mejores puestos de trabajo, dado el aprendizaje acumulado y la obtención de mejores niveles académicos. Angulo, Quejada y Yanés (2014) señalan que "el tema de posición ocupacional es importante al ser indicio de mejores ingresos y/o mayor satisfacción laboral” (p.150), y que por nivel 
académico hay mejoras salariales, por tanto con un posgrado se obtendrán niveles laborales superiores que con un pregrado. Por su parte, García (2003) menciona que "la educación es un factor clave en el nivel de satisfacción del individuo en el mercado laboral, puesto que contribuye a que el trabajador tenga mayores ingresos y encuentre un buen empleo" (p. 76).

\section{Características académicas que profesionales en turismo necesitan para un mejor desempeño laboral}

A partir del momento en que una persona obtiene un título universitario y se enfrenta al mundo laboral, se inicia un proceso mediante el cual se ponen en práctica las habilidades y conocimientos adquiridos, así mismo, sus acciones profesionales guiadas entre otras cosas por los principios, objetivos y prácticas de su formación académica, empiezan a generar cambios en el contexto social; de este modo, se logran atender las necesidades que la sociedad requiere y el turismo no es la excepción.

Las experiencias vividas durante el proceso de inserción y permanencia en el mercado laboral constituyen una forma de analizar la efectividad de los planes de estudio universitarios en respuesta a las necesidades del contexto social, información indispensable para los procesos de autoevaluación y retroalimentación que las autoridades de las instituciones de educación superior deben considerar para mejorar la calidad de la educación. En la Figura 6 se muestra la opinión del estudiantado graduado sobre los conocimientos académicos que requiere para mejorar su desempeño laboral.

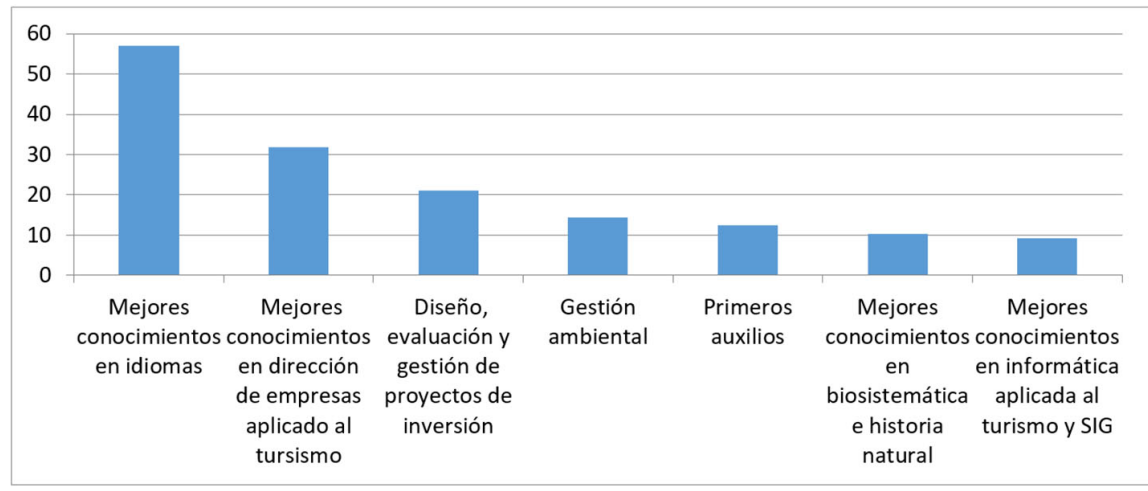

FIGURA 6

Opinión del estudiantado graduado sobre los conocimientos académicos que se requieren para un mejor desempeño laboral. Elaboración propia.

Mejorar los conocimientos en idiomas como el inglés u otros como el francés o el alemán encabezan la lista de conocimientos académicos que se requieren para un mejor desempeño laboral de las personas graduadas, con un 56,97\%. Las mejoras en el manejo de idiomas encabezan la lista de necesidades, en particular durante los primeros años de vida profesional donde se adolece de experiencia laboral, el mercado del turismo es dinámico y como ya se ha mencionado, presenta un constante crecimiento. La propuesta de Ruíz Navarrete (2013) coincide con la opinión del grupo graduado. Este, como docente de la carrera de Turismo Ecológico en el área de inglés, fundamenta la necesidad de rediseñar los cursos de inglés conversacional, de modo que estos se conviertan en una herramienta efectiva que les permita a las nuevas generaciones desarrollar mejor sus habilidades y competencias profesionales. Él mismo basa su propuesta de enseñanza en inglés para fines específicos.

Debe anotarse que los principales mercados de turismo de Costa Rica lo conforman países como Estados Unidos y Canadá, donde el idioma inglés es el predominante, así mismo, hay otros mercados emergentes 
como Alemania y Francia que requieren de profesionales capaces de brindar servicios de alta calidad, para lo cual la comunicación en sus idiomas nativos es indispensable (Instituto Costarricense de Turismo, 2015).

El 31,87\% de la población de profesionales coincide en que requieren adquirir mejores conocimientos sobre la dirección de empresas turísticas, condición que les permitiría afrontar como mayor experticia puestos administrativos de mayor responsabilidad dentro de la estructura organizacional de las empresas del sector turismo, así como facilitar la toma de decisiones en temas como finanzas, contabilidad y proyectos de inversión, mercadeo y el manejo de recursos humanos. Esta necesidad, si bien es cierto no es compartida por la mayoría, representa una prioridad para lograr la incidencia de la carrera sobre las empresas del sector turismo y así lograr desarrollar la actividad turística de una manera más responsable.

En tercera instancia se tiene que un que $21,12 \%$ de las personas requieren de nuevos conocimientos en materia de evaluación, diseño y manejo de proyectos de inversión turística, aspecto ligado a la capacidad de generar asesorías y consultorías dirigidas a entes emprendedores que buscan crear sus propios negocios, situación bastante común en las comunidades rurales donde el turismo forma una importante oportunidad de generar nuevos ingresos. A continuación se presenta la Figura 7, con información referente a la opinión de la población graduada sobre las habilidades que se requieren para un mejor desempeño laboral.

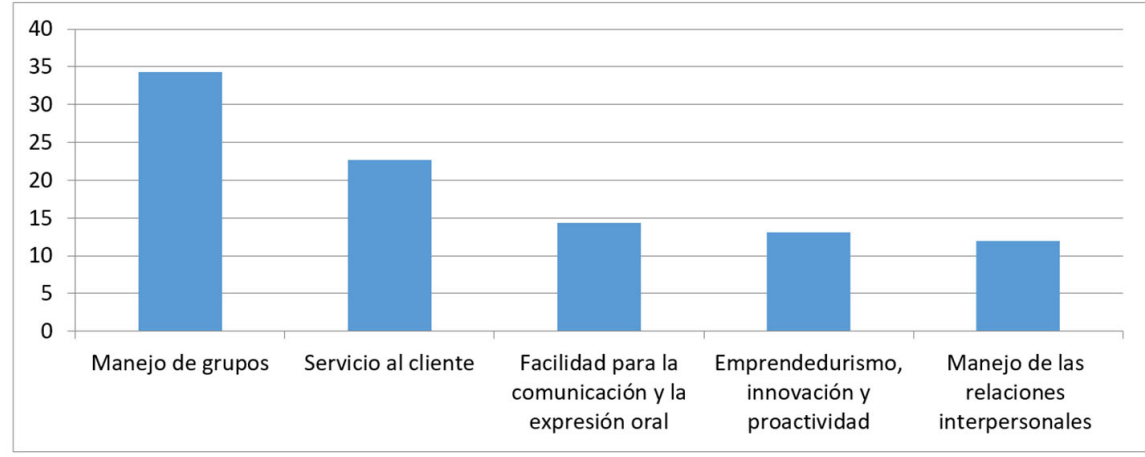

FIGURA 7

Opinión de la población graduada sobre las habilidades que se requieren para un mejor desempeño laboral. Fuente: Elaboración propia.

Sobresale la necesidad de mejorar habilidades en cuanto al manejo de grupos, con un 34,26\%, seguido por la necesidad de mejores habilidades en servicio al cliente $22,71 \%$, comunicación y expresión oral, emprendedurismo, innovación y proactividad, así como las relaciones interpersonales; sin embargo, no se evidencia una coincidencia de una mayoría representativa.

\section{Áreas prioritarias del contexto donde la carrera debe de incidir}

La Universidad de Costa Rica es una institución autónoma que busca incidir en el desarrollo nacional mediante un sinnúmero de acciones enmarcadas en tres grandes áreas como la docencia, la investigación y la acción social. Al analizar la experiencia del grupo de profesionales en turismo ecológico, quienes están en contacto directo con el contexto social que engloba a esta disciplina, se logran identificar diversos ejes o áreas prioritarias donde la institución debe incidir.

Tal como menciona Ramírez Domínguez, Reséndiz Ortega y Reséndiz Ortega (2016), el seguimiento de estudiantado egresado es una vía para fortalecer la vinculación entre la universidad con la sociedad y sobre ello indican:

No solo es un puente necesario entre las instituciones de educación superior y el mercado laboral sino también contribuye al desarrollo de la responsabilidad social universitaria porque a través de este programa la institución se reconecta con el 
contexto social, y reencuentra su identidad con los egresados con quienes tiene el compromiso de seguir brindando formación continua pertinente para mejorar su desempeño. (p. 1021)

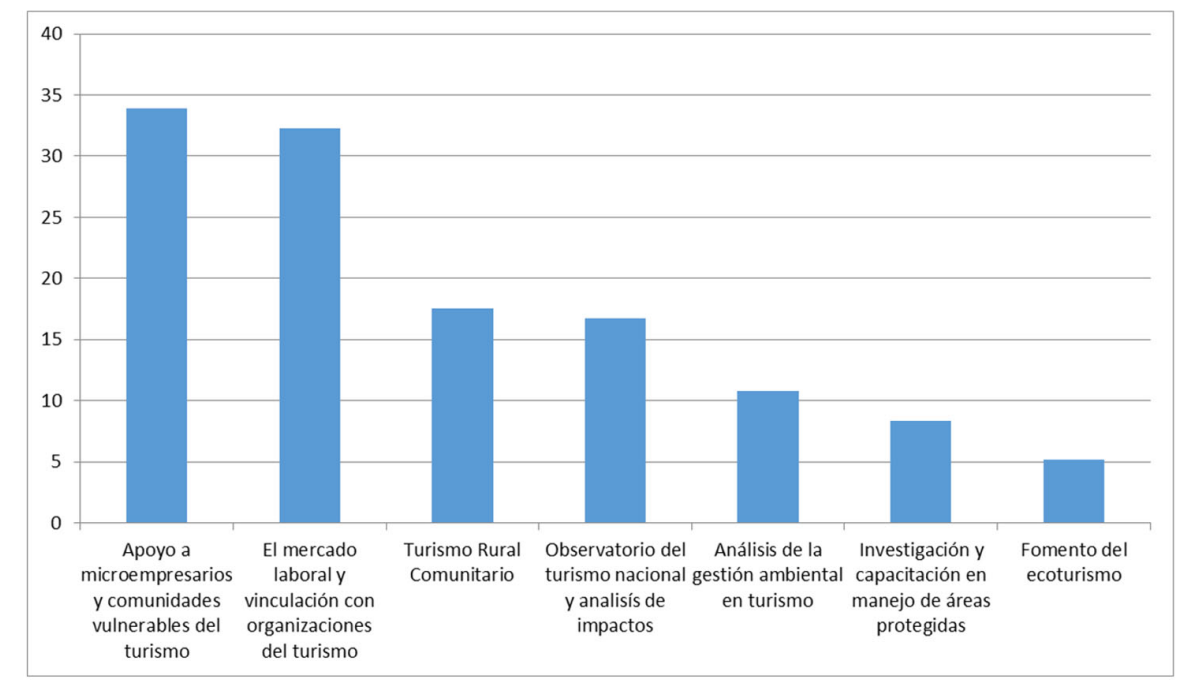

FIGURA 8

Opinión de la población graduada sobre las áreas del contexto en las cuales la carrera de Turismo Ecológico debe incidir. Fuente: Elaboración propia.

En la Figura 8 se muestra cómo las personas graduadas manifiestan una amplia gama de ideas y temas de trabajo. Se presentan como las de mayor coincidencia "apoyar a los microempresarios y comunidades vulnerables del turismo", la cual comprende las comunidades vulnerables como aquellas en las cuales se evidencian consecuencias negativas del modelo de desarrollo turístico o aquellas que pretenden incursionar en turismo como fuente de desarrollo responsable; este sector presenta diversas necesidades de capacitación y asesoría, en temas como la planificación y el manejo del turismo, el diseño de proyectos de inversión turística, mercadeo y relaciones públicas. Estas observaciones son relevantes en un país en el que el modelo de desarrollo impulsado en los últimos años no ha surtido efectos directos sobre el desarrollo humano; por el contrario, ha generado mayores tasas de desempleo, aumento de la población en condición de pobreza y una importante migración desde el campo hacia la ciudad, en especial hacia Valle Central (Román y Morales, 2015).

Honey, Vargas y Durham (2010) analizaron las repercusiones del turismo en comunidades y menciona que el crecimiento del turismo residencial en las zonas costeras está modificando el paisaje y desplazando o compitiendo por recursos con comunidades pesqueras, agrícolas y ganaderas; este turismo, a gran escala y orientado hacia el mercado de masas, pone en conflicto la reputación internacional de Costa Rica como un destino de naturaleza. El mismo estudio refiere la necesidad de demarcar con cuidadosa planificación y delimitación las actividades de turismo masivo, además cita de manera textual: "Se requiere más investigación de campo, recolección de información y análisis para determinar cuidadosamente la cantidad y calidad de los trabajos generados por los negocios relacionados con el turismo" (p. 86).

La segunda área donde se debe trabajar mediante la investigación y la acción social en materia de turismo se relaciona con la necesidad de incidir sobre el mercado laboral y generar mayores vínculos con organizaciones públicas y privadas afines. Sobre ello puede mencionarse como prioritario el identificar las principales fuentes de empleo, las condiciones laborales, estimular la contratación de personas graduadas de esta disciplina en puestos estratégicos sobre la toma de decisiones, sobre la planificación, el manejo y la evaluación del turismo.

En adición a estos ejes de trabajo se logra determinar un conjunto de temas relacionados con la identificación de mecanismos para lograr estimular modelos de desarrollo turístico que generen un mayor aporte al desarrollo local sostenible, tal es el caso, del turismo rural comunitario, el análisis de los impactos 
positivos y negativos del turismo, los instrumentos metodológicos de turismo sostenible y de gestión ambiental, y el manejo de turismo en áreas silvestres protegidas.

Las necesidades del contexto que se mencionan coinciden con las aspiraciones que el país ha establecido en materia de turismo y que han sido materializadas, dentro del Plan Nacional de Turismo 2010 - 2016, como parte fundamental del modelo de desarrollo turístico que se desea impulsar, que involucra buscar un uso sostenible de los recursos naturales y humanos, una distribución más equitativa de los recursos, para generar beneficios para el desarrollo humano de las poblaciones locales; es decir, el turismo es la principal herramienta para impulsar el desarrollo sostenible en Costa Rica (Instituto Costarricense de Turismo, 2012). Sin embargo, a pesar de que esas necesidades ya han sido identificadas por el ente rector del turismo en el país, muchas aún no han sido subsanadas y requieren de esfuerzo mayor para lograr ver cambios tangibles en la sociedad; esfuerzos que, sin lugar a dudas, requieren de una mayor articulación interinstitucional entre el sector académico, el sector privado y el gobierno.

\section{Mecanismos para fortalecer la inserción y la permanencia dentro del mercado laboral}

Al analizar las formas sobre cómo mejorar la inserción y la permanencia del mercado laboral, que se muestran en la Figura 9, sin lugar a dudas el tema en donde existe una mayor coincidencia es en la importancia de mejorar el plan de estudios de la carrera de Turismo Ecológico con un 85,26\%, para lo cual se considera que los propósitos con los cuales se crea esta disciplina son los indicados; sin embargo, se requiere una actualización de la malla curricular, de modo tal que se incremente el nivel de aprendizaje del idioma inglés, así como que se generen diversas especializaciones en temas prioritarios acordes con las necesidades del contexto y que cada especialidad, además, disponga de una serie de cursos optativos relacionados con su enfoque, y que para todos los casos se diseñe una modalidad de práctica supervisada, la cual se pueda desarrollar en instituciones públicas vinculadas al turismo, en organizaciones no gubernamentales, en áreas protegidas o empresas líderes del turismo nacional y regional.

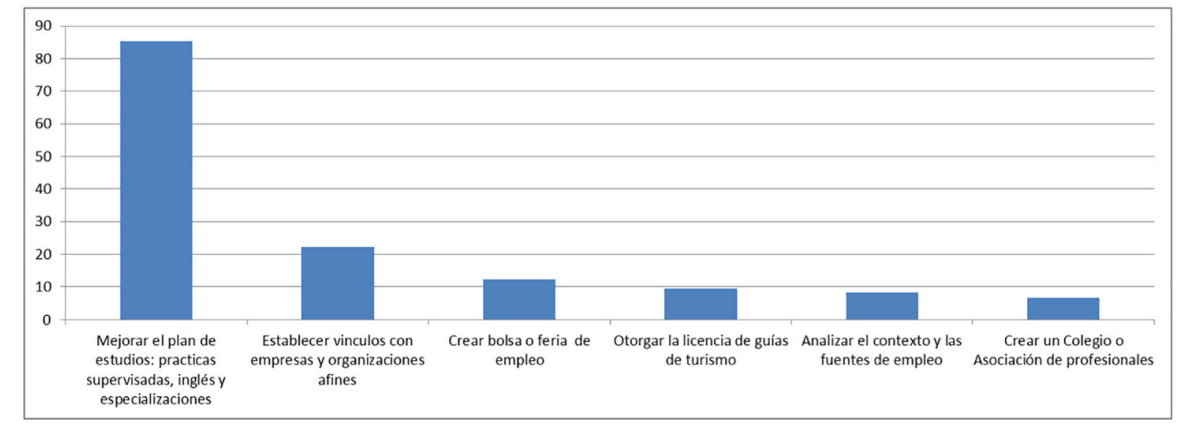

FIGURA 9

Opinión de la población graduada sobre las acciones para fortalecer la inserción y la permanencia en el mercado laboral. Elaboración propia.

Los principios de la carrera responden hoy más que nunca a las necesidades del contexto, a crear soluciones viables para las economías locales, favoreciendo las regiones mediante la generación de empleo. En esta misma línea, Arce y Chaverri (2015), en su estudio: El turismo en Costa Rica: Análisis de impacto sobre el desarrollo sostenible, señalan la necesidad de un replanteamiento de la estrategia de desarrollo del sector global y nacional, para que contribuya verdaderamente en la consolidación de un desarrollo sostenible, pues se plantean retos en cuanto a la sostenibilidad ambiental, social y económica, que favorezcan el desarrollo de hoteles pequeños, con mayor contacto entre turistas y las comunidades locales, así como actividades más auténticas. 


\section{Conclusiones}

En relación con la carrera de Turismo Ecológico en la Universidad de Costa Rica y la información obtenida desde la perspectiva de 251 personas, quienes conformaron la muestra representativa de la población graduada, se ha logrado poner de manifiesto los diversos logros y retos que deben ser abordados como parte de la gestión administrativa y, sobre todo, académica de esta profesión. Los aportes de la población participante puntualizan aspectos vinculantes, relacionados con la necesidad de actualización del plan de estudios, la gestión de la carrera, la investigación, la acción social y el contexto social nacional de esta disciplina.

Los resultados obtenidos coinciden con la experiencia desarrollada como parte del proceso de autoevaluación de la carrera de Turismo Ecológico, el compromiso de mejoramiento, el aumento en la cantidad de estudiantado graduando, su percepción y las condiciones tan versátiles del contexto turístico costarricense, lo cual evidencia la necesidad de actualizar el plan de estudios del bachillerato, de manera integral para toda la institución, como propuesta de la Universidad de Costa Rica al modelo de desarrollo turístico del país; en esencia, a partir de los conocimientos habilidades y actitudes puestos en práctica, el plan de estudios es pertinente y responde a las necesidades del contexto global, nacional y local. Sin embargo, debe considerarse la importancia de generar distintas especializaciones de formación a nivel de licenciaturas por cada región donde se imparte la carrera, acordes con las necesidades que las personas graduadas han evidenciado, como herramientas para competir en el mercado laboral.

Tal y como se mencionó el $85 \%$ de la población titulada en Turismo Ecológico, coincide en que se requiere de una formación profesional con mejores conocimientos en idiomas como el inglés u otros, prácticas profesionales en puestos a los que se ostentan, cursos optativos y especializaciones a nivel de grado, acordes con las necesidades de la sociedad y el mercado laboral, como son: manejo de grupos turísticos, administración de empresas turísticas, así como, educación turística.

Existen ciertos conocimientos o habilidades incluidos en la carrera que tienen poca aplicabilidad en el ámbito laboral, como lo son: los instrumentos metodológicos del ecoturismo, fijar prioridades y políticas para promover el turismo o desarrollar estrategias de crecimiento para empresas turísticas; mientras tanto, existen otras como, relacionarse y comunicarse armoniosamente de manera interpersonal con turistas o personas afines al turismo y utilizar los recursos naturales, que son altamente aplicadas. Por lo anterior, surge la necesidad de buscar incidir en mayor medida sobre el modelo de desarrollo turístico y el mercado laboral, para estimular la generación de puestos de trabajo donde se apliquen con mayor frecuencia los conocimientos y habilidades de la planificación, el manejo, la evaluación y la gestión del turismo.

Se requiere generar un mayor esfuerzo en materia de investigación y acción social, en función de los objetivos que fundamentan el quehacer de esta disciplina, coordinados de forma estratégica, para generar una mayor incidencia sobre el turismo nacional y local y brindar opciones reales de crecimiento, orientadas por los principios del desarrollo sostenible.

Los principios de la carrera responden hoy más que nunca a las necesidades del contexto, pero se deben promover más estudios que permitan develar nuevos métodos o mecanismos para que esta disciplina logre incidir en el modelo de desarrollo turístico, por medio de la colocación de su estudiantado graduado en puestos de gestión, planificación y toma de decisiones, alejándose de la competencia por puestos de trabajo que afianzan el subempleo en la disciplina, enfocados la mayor parte del tiempo en la atención de turistas, lo cual les puede generar una mala percepción de su formación. Es necesario un proceso de monitoreo y mejoramiento continuo sobre el desarrollo de la carrera de manera integrada, o bien por sede y recinto.

Se evidencia que el enfoque de formación profesional de la carrera de Bachillerato en Turismo Ecológico de la Universidad de Costa Rica se rige por los principios del desarrollo sostenible; sin embargo, contrasta con la realidad del modelo turístico costarricense que ha sido dirigido en su mayoría en función del sector empresarial y ha obedecido a intereses principalmente económicos. Esta situación genera que las personas graduadas afronten confusiones acerca de las competencias de su perfil profesional dentro del mercado 
laboral. Es hasta los últimos años cuando la política pública en materia de turismo, tanto nacional como internacional, se ha enfocado hacia la gestión sostenible de la actividad, lo que debería facilitar y aligerar la colocación de la población graduada en trabajos que reflejen más el perfil profesional para el que fue formada.

\section{ReFERENCIAS}

Almonacid, P., Montes, I. y Vásquez, J. (2009). Un análisis factorial para evaluar la pertinencia de un programa académico desde la perspectiva de los graduados: Un estudio de caso. Ecos De Economía, 13(29), 98-126. Recuperado de http://search.proquest.com/docview/1313173363?accountid=28692

Angulo Pico, G., Quejada Pérez, R. y Yanés Contreras, M. (2014). Ingresos adecuados y satisfacción laboral: análisis probabilístico basado en una encuesta a graduados de educación superior en Colombia. Trabajo y sociedad, (22). Recuperado de http://www.unse.edu.ar/trabajoysociedad/22\%20ANGULO\%20PICO \%20ingresos\%20adecuados\%20satisfaccion\%20laboral.pdf

Ansorena, A. (2015). La evolución de la educación superior. En I. Román Vega (Coord.), Quinto informe del estado de la educación (pp. 183-248). San José, Costa Rica: Programa del Estado de la Nación.

Arce, R. y Chaverri, M. (2015). El turismo en Costa Rica: Análisis de impacto sobre el desarrollo sostenible. Alajuela, Costa Rica: INCAE Business School.

Arrieta Murillo, G. y Rivera Hernández, G. (2011). La carrera de Turismo Ecológico de la sede de Guanacaste y el desarrollo del ecoturismo en la Universidad de Costa Rica. Intersedes, 7(13), 41-53. Recuperado de http:// www.revistas.ucr.ac.cr/index.php/intersedes/article/view/918/979

Comisión de Autoevaluación de Turismo Ecológico. (2013). Informe de autoevaluación del Bachillerato en Turismo Ecológico y Licenciatura en Gestión Ecoturística (Manuscrito inédito). San José, Costa Rica: Centro de Evaluación Académica, Universidad de Costa Rica.

Comisión de Autoevaluación de Turismo Ecológico. (2014). Compromiso de mejoramiento de la carrera de Bachillerato en Turismo Ecológico y Licenciatura en Gestión Ecoturística (Manuscrito inédito). San José, Costa Rica: Centro de Evaluación Académica, Universidad de Costa Rica.

Consejo Nacional de Rectores, Oficina De Planificación De La Educación Superior. (1990). Segundo dictamen sobre la solicitud de creación de la carrera de Turismo Ecológico (Bachillerato) en la Sede Regional de Guanacaste de la Universidad de Costa Rica (Reporte N. OOPES-22/90). San José, Costa Rica: CONARE.

Damián Simón, J. y Arellano Mont, L. (2009). Calidad profesional del técnico superior universitario en administración. Una visión de graduados y de empleadores. Actualidades Investigativas en Educación, 9(2), 1-30. Recuperado de http://revistas.ucr.ac.cr/index.php/aie/article/view/9542

García Mora, M. (2003). Efectos de la educación sobre los determinantes de la satisfacción laboral en España. Un análisis de los beneficios monetarios y no monetarios en el mercado de trabajo mediante modelos logit ordenados. (Tesis para optar por el grado de Doctor en Economía), Universitat de Valencia, España.

Global Sustainable Tourism Council. (2016). Our History [Nuestra Historia]. Recuperado de https:// www.gstcouncil.org/en/about/gstc-overview/our-history.html

Guédez, V. (1980). Lineamientos académicos para la definición de los perfiles académicos. Revista Currículum, 5, 1-32.

Gutiérrez Coto, I. Kikut Valverde, L. Navarro Cerdas, G. Azofeifa Ureña C. y Rodríguez Ramos, N. (2015). Seguimiento de la condición laboral de las personas graduadas 2008-2010 de las universidades costarricenses (Reporte N. OOPES-06/2015). San José, Costa Rica: CONARE, Oficina de Planificación de la Educación Superior, Observatorio Laboral de Profesiones.

Hernández, R. Fernández, C. y Baptista, P. (2014). Metodología de la Investigación (6º ed.). DF. México: Mc Graw Hill Education.

Honey, M., Vargas, E. y Durham W. (2010). Impacto del turismo relacionado con el desarrollo en la costa pacífica de Costa Rica. San José, Costa Rica: Center for Responsible Travel. 
Instituto Costarricense de Turismo. (2007). Plan Nacional de Turismo Sostenible de Costa Rica 2002 - 2012 (Actualización al 2006). San José, Costa Rica: Autor.

Instituto Costarricense de Turismo. (2012). Plan Nacional de Turismo Sostenible de Costa Rica 2010 - 2016. San José, Costa Rica: Autor.

Instituto Costarricense de Turismo. (2015). Anuario Estadístico de Turismo 2014. San José, Costa Rica: Autor. Recuperado de http://www.ict.go.cr/es/estadisticas/informes-estadisticos.html\#2005-2014

Oficina de Registro e Información de la Universidad de Costa Rica. (2014). Reporte del Sistema de Aplicaciones Estudiantiles sobre estudiantes graduados de la carrera de Bachillerato en Turismo Ecológico y Licenciatura en Gestión Ecoturística. San José, Costa Rica: Autor.

Ramírez Domínguez, M., Reséndiz Ortega, M. y Reséndiz Ortega, M. (2016). Metodología de seguimiento de egresados para fortalecer la vinculación de la universidad con la sociedad. Global Conference on Business and Finance Proceedings, 11(1), 1021-1026. Recuperado de http://search.proquest.com/docview/1765858710? Accountid $=28692$

Roldán Santamaría, L. (2005). Elementos para evaluar planes de estudio en la educación superior. Educación, 29(1), 111-123. Recuperado de http://www.redalyc.org/articulo.oa?id=44029111

Román M. y Morales, N. (2015). Equidad e integración social. En Programa del Estado de la Nación, Vigésimo Primer Informe del Estado de la Nación (pp. 73-126). San José, Costa Rica: Programa del Estado de la Nación.

Ruetzlera, T., Bakerb, W., Reynoldsc, D., Taylora, J. y Allen, B. (2014). Perceptions of technical skills required for successful management inthe hospitality industry-An exploratory study using conjoint analysis [Percepciones de los conocimientos técnicos necesarios para una gestión exitosa en la industria de la hospitalidad-Un estudio exploratorio utilizando el análisis conjunto]. International Journal of Hospitality Management, 39(2014), 157 - 164. doi: 10.1016/j.ijhm.2014.02.012

Ruíz Navarrete, R. (2013). Propuesta para el rediseño del curso TE-0300 inglés conversacional I en turismo ecológico: Universidad de Costa Rica - Sede de Guanacaste. Intersedes, 15(30), 69-94. Recuperado de https:// revistas.ucr.ac.cr/index.php/intersedes/article/view/14870/14147

Silas Casillas, J. (2013). Acreditación mercado y educación superior. Reencuentro, 67(1), 17-25. Recuperado de http:// www.redalyc.org/articulo.oa?id=34030523003

Suárez Lantarón, B. (2014). La universidad española ante la empleabilidad de sus graduados: Estrategias para su mejora. Revista Española de Orientación y Psicopedagogía, 25(2), 90-110. Recuperado de http://www.redalyc.org/ articulo.oa?id=338232663007

Universidad de Costa Rica, Consejo Universitario. (1974). Estatuto Orgánico de la Universidad de Costa Rica. Gaceta N. ${ }^{\circ}$ 52. San José, Costa Rica: Gaceta Universitaria.

Universidad de Costa Rica, Vicerrectoría de Docencia. (1991). Apertura del Bachillerato en Turismo Ecológico. (Resolución N. 4880-90). San José, Costa Rica: Autor.

\section{BY-NC-ND}

